\title{
The Impact Analysis of Augmented Reality and Virtual Reality in Education
}

\author{
Tanvi Vijay, Mohit Anand, *Divya Udayan J, Anupama K Ingale
}

\begin{abstract}
Currently, Augmented Reality (AR) and Virtual Reality (VR), are the most disruptive and popular technologies that predominates in every aspects of industry domain. These technologies provide users a visual treat that basic technologies like $2 D$ and $3 D$ have not been able to provide so far. They have extended their realm in all domains of life, from providing the opportunity to visit the Taj Mahal while you are sitting in your living room to finding the correct furniture for your office. The recent update is coming from the world of education, where $A R / V R$ is being implemented to make learning a better experience for all. This technology is being used to make applications that make the process of understanding easier and more likeable for students. For increasing the student motivation, research on AR has showed its extreme usefulness in the process of learning. In this paper we have studied the impact of AR/VR applications on education and it's benefit while comparing it to the traditional method of teaching using textbooks. We devised various types of evaluation techniques and distributed it to people of all age group and backgrounds. We evaluated the $U X$ by providing the audience to first use a commercial AR/VR application and then record their experience. The results are analyzed in our work and suggestions given to further enhance our study to make the combination of technology and education a success.
\end{abstract}

Index Terms: Augmented Reality, Education, Impact Analysis, User Experience (UX), Virtual Reality.

\section{INTRODUCTION}

In recent years, technologies like Virtual Reality (VR), Augmented Reality (AR) are used in the education field like in medical, archaeology, engineering, sawbones etc., for example Giza project at Harvard [1] under this project the pyramids of Giza plateau 3D models are create and used in several courses on Pyramids of Giza: Ancient Egyptian Art and Archaeology, offered through Harvard X, using both an immersive 3D stereo display lab and 3D headsets. Virtual reality gives the user an immense experience of the virtual world. The user can interact with the objects in the virtual world. Thus, students can enjoy the learning and at same time they can involve in the subject. According to, Goldman Sachs [1] research experts a huge amount approximately $\$ 80$ billion will be invested in AR/VR applications by 2025 in which education sector has an investment of $\$ 700$ million.

AR supplements the physical world with interrelated synthetic data, allowing virtual and physical objects to cohabit in an

Revised Manuscript Received on July 05, 2019.

Tanvi Vijay, School of Information Technology and Engineering, Vellore Institute of Technology,Vellore,India.

Mohit Anand, School of Information Technology and Engineering, Vellore Institute of Technology,Vellore,India.

*Divya Udayan J (Corresponding Author), School of Information Technology and Engineering, Vellore Institute of Technology,Vellore,India.

Anupama K Ingale, School of Information Technology and Engineering, Vellore Institute of Technology,Vellore,India. augmented space area [2]. AR is extensively used in the field of construction process [3]. Various applications AR based applications and systems for on-site tasks such as data visualization and work inspection [4] are developed. These developments have improved on-site safety performance to some scope. A few studies have also attempted to adapt VR and $\mathrm{AR}$ in construction training and learning. The real time application of AR/VR can be developed in every sector, and one such sector is education. AR/VR can be used in education to let students interact with digital world to have a better understanding of concepts on its visuals and working making it more interesting for them and helping them in gain knowledge in better way. Revolutionizing the education with AR/VR could be one the major advancements in the $21 \mathrm{st}$ Century where the biggest benefit would be for the student where they would be encouraged for more practical based learning through experience and active participations not just by memorization and writing exams[5].

\section{BACKGROUND}

From studying and writing on slates with the chalks to using laptops for study, technology is constantly pushing the limits of educational capabilities to new levels. The kind of advances utilized in instruction greatly affects its effort. When the Chalkboard came around in 1890 , trailed by the pencil in 1900, unmistakably understudies were eager for further developed instructive devices [6]. With advancements are being made in the educational world that will enhance its outreach. When people used slates in education no one imagined that there will be a day when they will be using pen and paper one day. There were a lot of limitations of using slates. The students couldn't keep anything as a record and always had to keep erasing their previous work to write new material. They were certainly in a need of new advancements in this field. Something that they can keep and refer to later, thus came paper all these were non-technological advancements, which still left a lot of understanding and learning up to students' imagination. The teachers, as well, needed something more advanced than a blackboard Educators required new techniques for guidance and testing, and learners were searching for better approaches to convey, think about, and learn [6].Thus, came computers and internet. Students can now learn, record, and store information a new and better way. Teachers started using smart boards to make lessons more interesting and fun. The depth of knowledge was easier to access than ever before, with YouTube and other online libraries making their way into classrooms.

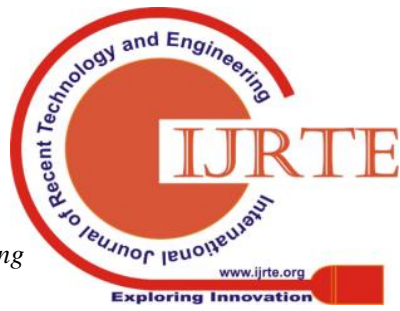


Next what was required from technology was a visual experience that will bring lessons to life for e.g. you no more need to imagine how a solar system looks like as you can experience it with your own eyes using Augmented or Virtual reality. This is the latest trend in the education industry. It is being implemented and many new applications are being developed related to education which can boost the learning power of any student.

Virtual Reality (VR) technology allows the user to interact with a computer generated scenario (virtual environment) and feel them to be the part of it. Virtual Environment may be categorized into four types: head mounted display, augmented, Fish Tank, and projection-based [7-9]. The basic VR device at least support $3 \mathrm{D}$ animation that can cause interactively at a mobile computer, commonly by a handle or the remote control so that the image of the digital content shift in some setting [10]. VR represents a novel move to a more complete sensorial involvement; it has been the subject of several applications in higher education, and professional development [11]. VR is used in enhancing the learning in various engineering area like in construction management where VR is used as a tool to enhance visio-spatial learning, on-demand training and distance learning [4].

Augmented reality (AR) is mix of virtual and physical environments. Appliance-based on this technology require three bases: tools to track information about physical environments, software and hardware to system computer and devices to show the human the virtual environment integrated into the physical environments [12]. AR technology is used in two different type one is an AR marker, which uses a marker to take virtual data; the second is AR location-based, which makes use of a GPS location-based to analyze locality at where virtual object data should be overlap. Deep learning of the student can also be triggered using digital story telling technique [13].

Aside from the review, a vast extent of other research papers demonstrates that for specific points, AR is more compelling at showing learner than contrasted with other media, for example, books, recordings, or work area experience in Personal Computer [14]. Vincenzi and his colleagues demonstrated that substance learned through an AR encounter is fundamentally more inclined to be reviewed weeks later, than contrasted with substance learned through paper or video media [15].As indicated by several surveyed research papers $\mathrm{AR} / \mathrm{VR}$ experiences, major improvement is seen in group collaboration [14].After certain periods of time, each industry needs a new revolution, a new technology that will cater to it's growing needs. Similarly, the education industry is in a dire need of new a technology that will offer new advancements to this world. AR/VR has been the talk of the town for a while and has slowly started to take over education world. AR is progressively achieving youthful learners, for example, grade school and secondary school learner, as their guardians and instructors wind up mindful of the innovation and its potential for training [14].Not only serious lessons but game-based learning is also technique that has already begun to effect classrooms. Virtual reality will probably completely change the way entertainment can be utilized for Game-based learning works since it builds commitment and inspiration, and virtual reality can take this to that level [16]. All things considered many things can be satisfied in the virtual world that would not be conceivable. Additionally, it is essential the visual and sensation encounters in virtual universes add to our capacity to learn [16].

\section{METHODOLOGY}

To study the adoptability of technology by the students we conducted an online survey. While creating the questionnaire for the survey we kept all the factors that may have an impact on adoptability of technology, in mind and included them in the form of different questions. The main questions for which we tried to find solutions were: Does AR/VR have a good impact on the field of Education?. In future what user expect from AR/VR to this education field? To find the answers to these questions, the response received from the questionnaire has been analyzed and then, they have been meaningfully summarized to obtain the end results.

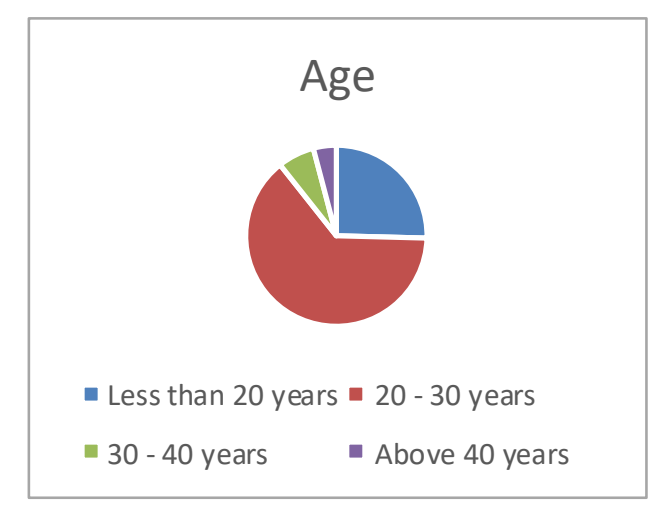

(a)

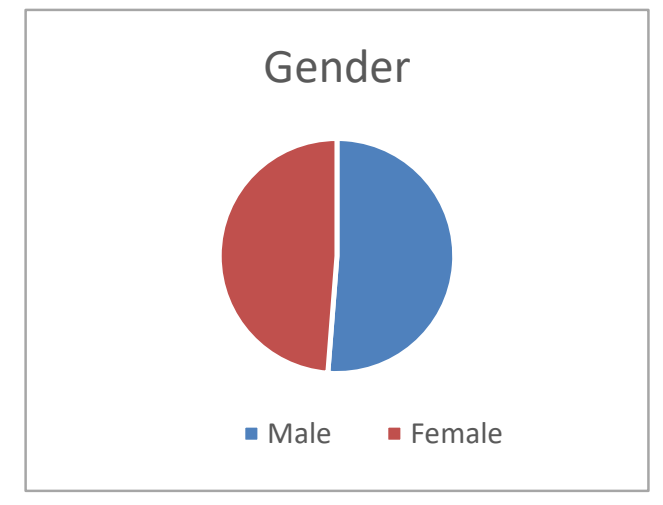

(b)

Figure 1: Demographic of the participants

Our primary goal was to include responses from groups of people belonging to all generations. Education is one factor that has impacted lives of all, in every sphere of the world, from our elders to the next generations. Thus, it was only befitting to get contributions from every age group in our survey so that the output is as balanced as possible. Hence we choose the participants from all the ages and the people who have basic technical knowledge. All those who participated in the survey had some basic knowledge about the technology in discussion but most of them had no personal experience of using it. Thus, before filling the survey, all the participants were asked to use a commercial AR/VR application (related to education) and completely understand what this technology has to offer. Many

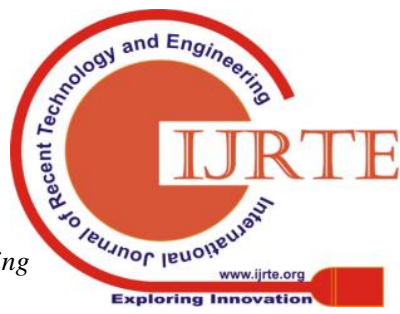


participants used iPhones, and a few owned Android smartphones. We got a total of 121 responses. No rewards were given to those who participated. The survey was conducted in English.

\section{DAta Collection AND Result Analysis}

The various questions that were asked were designed keeping 3 key factors learning experience, ease of use of applications and expected future improvement. The collected responses are as follows:

\section{A. Learning Experience}

The participants were asked about their experience while using VR and AR application. This was done to find out what kind of improvements, if any, in user experience does this technology provides. A good user experience is essential for any technology, without which the entire purpose of developing is of no use. Survey questioner were framed to know user learning experience and accordingly options ranging from very easy to very difficult were framed. Majority of the participants felt that it was easier to understand the subject in discussion after using the application as compared to textbooks. This indicates that the use of AR/VR can surely contribute in improving the quality of education we have to offer as shown in fig 2 .

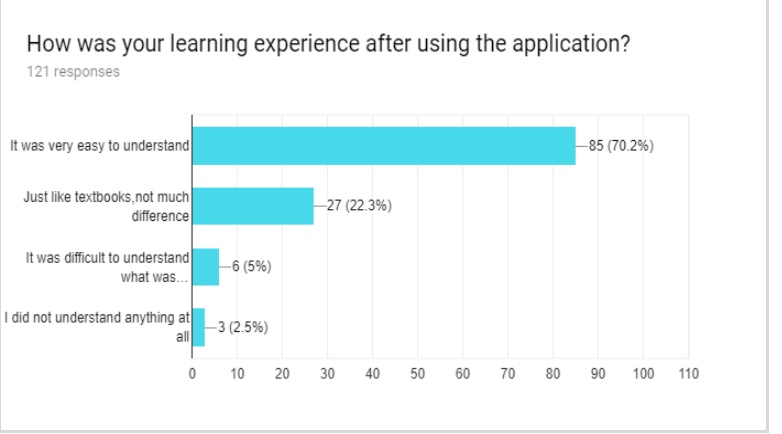

Figure 2: Learning experience.

\section{B. Ease of Use}

An important factor which is often included while evaluating a technology is the ease of use with which the users can work with it. For any new technology to thrive in the market, it is necessary that it connects with the audience. This is only possible when the users are comfortable while using it. Moreover, if the developer wishes to attract a large audience then they should focus on making the application easy to use, as well as understand, so that people of all ages can work with it. We framed questioner to address the user adoption to the application. Majority of them have found the application to be easily adopted and were user friendly.

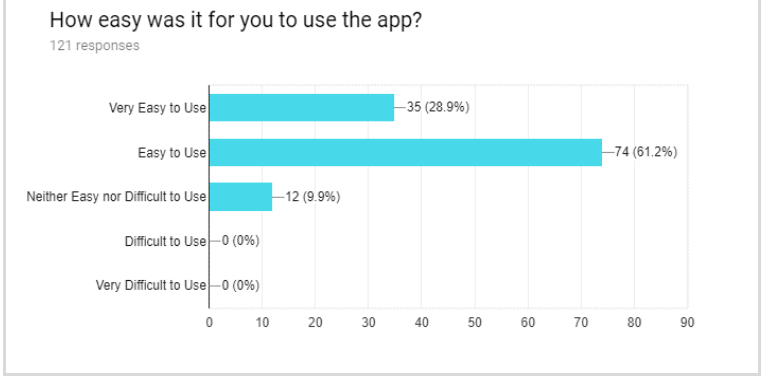

Figure 3: Easiness level.
Next, we asked the participants to tell us the duration for which they can use software for. Majority of them felt that they can use this app for about 15 minutes to half an hour. This limited usage may be because of the pressure it puts on your eyes. While most of the people can read from a book for hours, they cannot spend the same amount of time in front of a screen.

How long will you this application for?

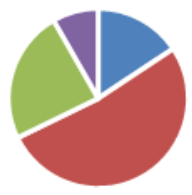

$$
\begin{aligned}
& \text { - Less than } 15 \text { mins }=15-30 \text { mins } \\
& =30-60 \text { mins }=\text { More than } 1 \text { hour }
\end{aligned}
$$

Figure 4: Time considerations

\section{Impact and Future Recommendations}

Lastly, to find what kind of impression does the users hold of the app and hence the technology, they were asked if they would recommend these types of applications related to AR/VR technology to others.

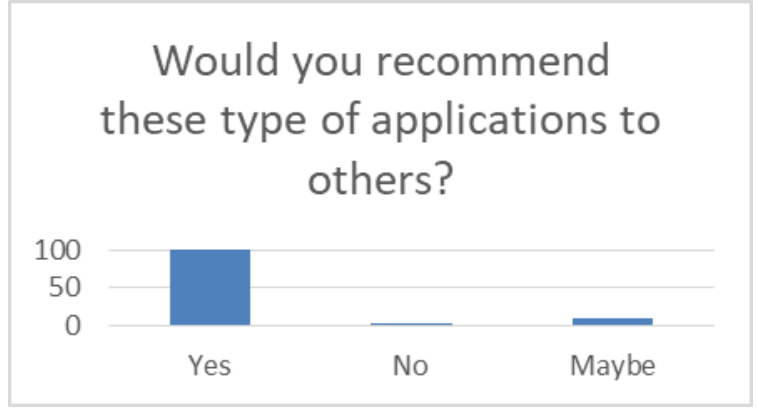

(a)

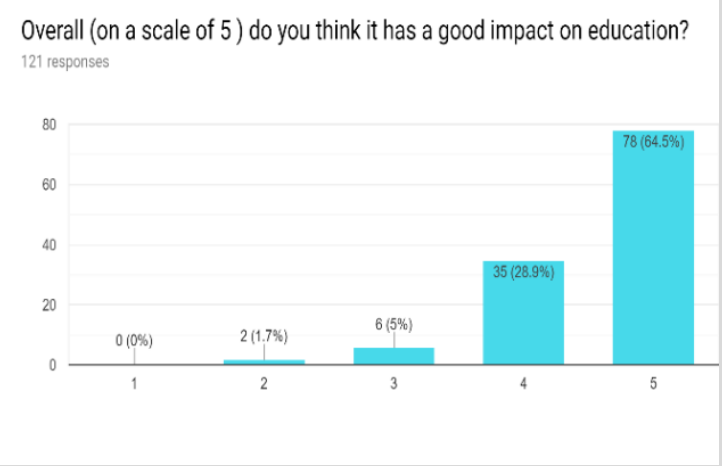

(b)

Figure 5: Impact of AR/VR.

The answer that received $92 \%$ of the votes was 'yes'. This certainly means that the application had a good impression on its users and hence the technology has a positive impact. Most of the people also agreed to replace the current technology with AR/VR. This shows that people are looking for a new revolution in education. They wish for an education system where learning and technology goes hand in hand.

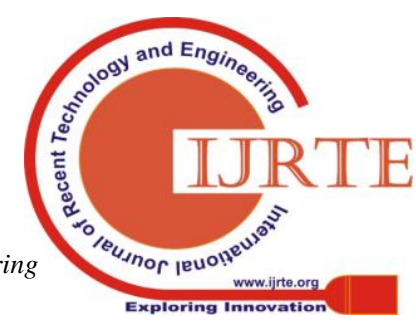


In future, do you want textbooks to be replaced by AR/VR technology? 121 response

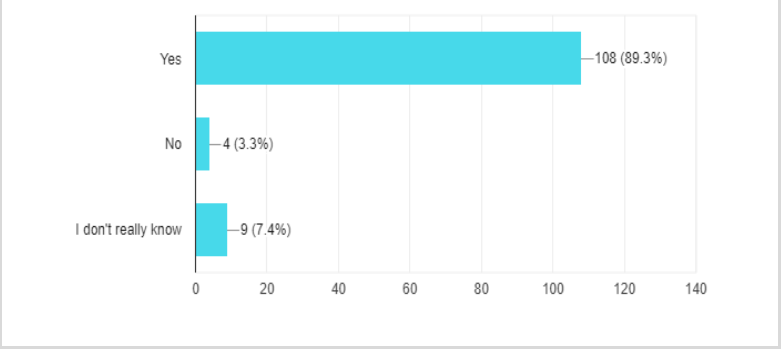

Figure 6: Influence of AR/VR.

\section{DISCUSSION}

The purpose of designing and analyzing the survey was to find that Does AR/VR Have A Good Impact On The Field Of Education? and In future what contribution can we expect from AR/VR to this field? . Through survey analysis shows that the people, of all generations, look at this new technique of teaching and learning as an improvement to what already exists. Also the people are able to readily adapt to this technique for teaching, as it helps students to understand the concept easily, and make class more interactive. We can expect very effective changes in the classrooms through AR/VR that offer enhanced learning and understanding to its users. The overall analysis shows that the AR and VR applications are fast adopted and $92 \%$ of the people out of 121 have agreed that the AR and VR application have an impact on education. Around $83 \%$ of the people like to replace textbook learning to interactive learning through AR/VR technology.

\section{CONCLUSION AND FUTURE WORK}

Many schools have also begun to use virtual field trips as a method of incorporating fun in teaching as well as learning. We can conclude that if worked on properly, this technology can completely change the game. Education will be much more than simply rote learning answers. It can seriously change the face of the education industry. But each coin has two sides, similarly every technology has its pros and cons.AR/VR may not have the same impact on everyone. While some may find it very useful, others with less knowledge about technology may fear using it and refrain from using it completely to prevent embarrassment of any sort. It may also lead to other problems like loss of attention and eyesight problems to students using it for longer intervals of time. Thus, we can say that Augmented and Virtual reality can be implemented in schools and higher educational institutes to facilitate enhanced learning. As of now, regular checks and restricted usage will be essential to ensure its smooth functioning.

\section{ACKNOWLEDGMENT}

The authors thank Vellore Institute of Technology for providing 'VIT SEED GRANT' for carrying out this research work.

\section{REFERENCES}

1. Kim, Jeffrey, Leathem, Tom. "Virtual Reality as a Standard in the Construction Management Curriculum". International Conference on Construction Futures, 2018.

2. Azuma T. R.. “A survey of augmented reality",Teleoperators and Virtual Environments, 1997. pp. 355-385.

3. Ramos, F.; Trilles, S.; Torres-Sospedra, J.; Perales, F.J. New Trends in Using Augmented Reality Apps for Smart City Contexts. ISPRS Int. J. Geo-Inf. 2018, 7, 478.

4. Park, Chansik, Lee, Do-Yeop, Kwon, Oh-Seong \& Wang, Xiangyu. “A framework for proactive construction defect management using BIM, augmented reality and ontology-based data collection template". Automation in Construction, 2013. pp. 61-7.

5. Elkoubaiti, Houda, Mrabet, Radouane, "A Survey of Pedagogical Affordances of Augmented and Virtual Realities Technologies in loT Based Classroom". IEEE 5th International Congress on Information Science and Technology (CiSt), 2018. pp. 334-341.

6. Misbhauddin, Mohammed "VREdu: A Framework for Interactive Immersive Lectures using Virtual Reality”. 21st Saudi Computer Society, National Computer Conference (NCC), 2018. pp. 1-6.

7. Keshner EA, Kenyon RV. "Using immersive technology for postural research and rehabilitation”. Assist Technol, 2004. pp.54-62.

8. Sherman $W$, Craig A. "Understanding virtual reality: Interface, application, and design”. Morgan Kaufmann Publishers Inc, 2002.

9. Stanney KM. Handbook of Virtual Environments: Design, Implementation, and Applications. New Jersey: Erlbaum Assoc, 2002.

10. Yasin, M. A., Darleena, Z., Mohd, A., Mohd, I., “Avatar Implementation in Virtual Reality Environment using Situated Learning for Tawaf". Procedia - Social and Behavioural Sciences, 2012. pp.73-80

11. Freina, Laura, and Michela Ott. "A literature review on immersive virtual reality in education: state of the art and perspectives." The International Scientific Conference eLearning and Software for Education. Vol. 1. " Carol I" National Defence University, 2015.

12. Webster $R$ "Declarative knowledge acquisition in immersive virtual learning environments". Interactive Learning Environments, 2016. pp.1319-1333.

13. Jantakoon, Thada, Wannapiroon, Panita, Nilsook, Prachyanun "Virtual Immersive Learning Environments (VILES) Based on Digital Storytelling to Enhance Deeper Learning for Undergraduate Students". Higher Education Studies, 2019. pp.144-150.

14. Radu, I. "Why should my students use AR? A comparative review of the educational impacts of augmented-reality" in IEEE International Symposium on Mixed and Augmented Reality (ISMAR), 2012. pp. 313-314.

15. Vincenzi, D. A., Valimont, B., Macchiarella, N., Opalenik, C., Gangadharan, S. N., Majoros, A. E. "The Effectiveness of Cognitive Elaboration Using Augmented Reality as a Training and Learning Paradigm". Proceedings of the Human Factors and Ergonomics Society Annual Meeting, 2003. Vol. 47, No. 19, pp. 2054-2058.

16. Liu, T.-Y., \& Chu, Y.-L. "Using ubiquitous games in an English listening and speaking course: Impact on learning outcomes and motivation." in Computers \& Education, 2010.pp. 630-643. 


\section{AUTHORS PROFILE}

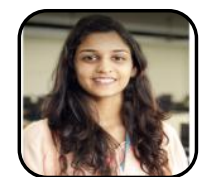

Tanvi Vijay is currently pursuing 4th year B.Tech in Information Technology from Vellore Institute of Technology, Vellore, India. UI/UX, Augment reality and Virtual reality has been her field of interest, trying her hands at creating game character, game stages design, mobile and web Application user interface has helped her to implement her idea and knowledge into other fields and motivated her to carry out her own research in the field her interest lies.

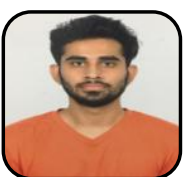

Mohit Anand is currently pursuing 4th year B.Tech in Information Technology from Vellore Institute of Technology, Vellore, India. His area of interest and research are in the domain of Virtual Reality, Augmented Reality and Artificial Intelligence. Being an avid gamer, the sheer curiosity of knowing the science behind the creation of games has driven him to gain expertise in the field and eventually create AR/VR games which he is so passionate about.

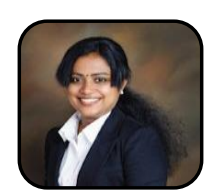

Divya Udayan $\mathbf{J}$ received the $\mathrm{PhD}$ degree in Internet and Multimedia Engineering from Konkuk University, South Korea. She is Associate Professor in the Department of Information Technology, VIT University, India. Her research interests include semantic modeling, image reality and $\mathrm{HCI}$ processing, recognition and classification, augmented

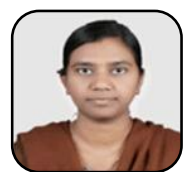

Anupama $\mathbf{K}$ Ingale is a research scholar in school of Information Technology and Engineering at Vellore Institute of Technology (VIT), Vellore, India. She has received M.Tech and B.Tech degree in Computer Science and Engineering from Visvesvaraya Technological University, Karnataka, India. Her research interests include Virtual Reality, Augmented Reality and Computer Vision. 